\title{
Trauma penetrante cardíaco en la unidad de emergencia del Hospital Carlos Van Buren*
}

\author{
Drs. GONZALO GÓMEZ C. ${ }^{1}$, JOSÉ HOLA B. ${ }^{1}$ \\ 1 Unidad de Emergencia, Hospital Carlos Van Buren, Valparaíso, Chile.
}

\begin{abstract}
Penetrating cardiac trauma. Review of 36 operated patients

Background: The most common cause of cardiac penetrating trauma is wounds caused by knives or firearms. Aim: To review the operated cases of penetrating cardiac trauma in a public hospital emergency room. Material and Methods: Review of medical records of patients operated for penetrating cardiac trauma between 1986 and 2009. Results: We retrieved the records of 36 patients (33 males) with a median age of 30 years. Ninety four percent of lesions were cause by knife wounds. In 24 patients, the right ventricle was injured. Immediate surgical mortality was $17 \%$ and $22 \%$ of patients had complications. Conclusions: Surgical mortality in penetrating cardiac trauma is related to the delay of surgical correction, injury by firearms or the presence of complex lesions.
\end{abstract}

Key words: Cardiac trauma, knife wound, cardiac surgery.

\section{Resumen}

El trauma penetrante cardíaco representa una de las mayores causas de muerte por motivo de violencia urbana y se clasifica en penetrante o contuso. La causa más común de trauma cardíaco penetrante es la herida por arma blanca o de fuego. La principal causa de trauma penetrante cardíaco en nuestra serie fue la lesión por arma blanca, siendo el ventrículo derecho la principal cámara cardíaca afectada. Los resultados quirúrgicos son comparables con otras series, con una mortalidad del $16,6 \%$ y una morbilidad de $22 \%$. La mortalidad quirúrgica está relacionada con el retraso de la cirugía, o la lesión por arma de fuego, o la presencia de lesiones complejas. Aún sigue siendo fundamental el diagnóstico clínico y el manejo precoz.

Palabras clave: Trauma penetrante cardíaco, trauma, corazón.

\section{Introducción}

La historia del traumatismo penetrante cardíaco ha sido descrita en todos los períodos de la historia, una de las más remotas aparece en las historias de la Iliada. Beck clasificó la historia del trauma cardíaco en 3 períodos. El primer período es el del misticismo, en donde las heridas cardíacas eran un misterio y la muerte era lo habitual. El segundo, que comienza en el siglo XVIII, se caracteriza por la observación y experimentación. El tercer período es el de la sutura y tiene su comienzo en 1882, período en el cual se describieron muchas de las actuales técnicas quirúrgicas ${ }^{1}$.

\footnotetext{
*Recibido el 9 de Junio de 2009 y aceptado para publicación el 20 de Julio de 2009.

Correspondencia: Dr. Gonzalo Gómez C.

Anélida 250, Jardín del Mar, Viña del Mar, Chile.

E-mail: gonzalogomezcorona@gmail.com
} 
En 1883 Theodore Billroth realizó dos célebres comentarios; "la pericardiocentesis es una operación que, en mi opinión, se aproxima mucho a lo que algunos cirujanos denominarían la prostitución del acto quirúrgico y otras locuras" y en el congreso de Viena señaló "aquel cirujano que trate de suturar alguna herida cardíaca perderá el respeto de sus colegas". El 7 de septiembre de 1896 un joven jardinero alemán, es agredido con un cuchillo cocinero en el tórax. La policía lo trasladó al Hospital Provincial de Frankfurt donde es recibido por el médico auxiliar, Dr. Siegel. El director, $D r$. Ludwig Rehn, se encontraba de viaje. A la pregunta de la policía, el Dr. Siegel, negó toda posibilidad de esperanza y ordenó a la enfermera que le diera al malherido una bolsa de hielo y alcanfor. El 9 de septiembre, el Dr. Rehn regresa al Hospital, y luego de examinar al moribundo jardinero decide arriesgarse, hasta entonces lo impensado, suturar una herida del corazón. Accedió por toracotomía lateral, en el 4to espacio izquierdo, drenó el hemotórax, abrió el pericardio y suturó el ventrículo derecho con 3 puntos de seda. La hemorragia cedió y el corazón continuó latiendo. Años más tarde presentó su caso en Berlín donde señaló "de hoy en adelante ya no podrá ponerse en duda la posibilidad de suturar el corazón".

El trauma penetrante cardíaco representa una de las mayores causas de muerte por motivo de violencia urbana y se clasifica en penetrante (abierto) o contuso (cerrado). La causa más común de trauma cardíaco penetrante es la herida por arma blanca o de fuego ${ }^{1,2}$. En nuestro medio sigue siendo la lesión del tórax con arma blanca la principal causa de traumatismo penetrante torácico ${ }^{3}$. La presentación clínica del trauma penetrante cardíaco es variable y la mortalidad depende de varios factores ${ }^{1,4}$. El objetivo del trabajo es evaluar los resultados quirúrgicos del trauma penetrante cardíaco en la Urgencia del Hospital Carlos Van Buren y presentar una revisión del tema.

\section{Material y Método}

Se realizó un estudio retrospectivo de revisión de casos clínicos desde febrero de 1986 a febrero de 2009, de todos los pacientes ingresados vivos y operados de trauma penetrante cardíaco en la Unidad de Emergencia del Hospital Carlos Van Buren de Valparaíso (Nivel de evidencia tipo III).

Una vez ingresado el paciente a la sala de reanimación, la indicación quirúrgica fue determinada según el criterio clínico de cada cirujano. El pabellón de urgencia se encuentra anexo a la sala de reanimación, por lo cual no se realizan toracotomías en el box de urgencias. Al no contar con esternótomo neumático, la estereotomía o toracotomía se realizan con el instrumental quirúrgico habitual de toracotomía. Todos los pacientes fueron operados por cirujanos de urgencia o residentes de último año. No se excluyó ningún paciente por datos incompletos de la ficha clínica.

Se registraron los datos demográficos, el tipo de arma, la presentación clínica en la urgencia, el abordaje quirúrgico, el sitio de lesión cardíaca, la morbilidad (toda complicación postoperatoria que requiriera tratamiento médico) y mortalidad de la serie (mortalidad temprana antes de 30 días). Debido a que en los primeros años de esta revisión no se aunaban conceptos claros en el manejo del trauma, definimos como colapso circulatorio la presencia de shock hipovolémico o paro cardiorrespiratorio al momento del ingreso del paciente. Los datos se analizan según estadística descriptiva y se presentan en porcentajes.

\section{Resultados}

Hubo 36 pacientes con trauma penetrante cardíaco, 33 hombres y 3 mujeres, la edad promedio fue 30 años. La principal causa de trauma penetrante fue la lesión por arma blanca (94\%), sólo se registraron 2 lesiones por arma de fuego.

La presentación clínica al ingreso en la sala de reanimación fue de colapso circulatorio en $33 \mathrm{ca}$ $\operatorname{sos}(92 \%)$.

El abordaje quirúrgico fue en el $80 \%$ por toracotomía anterolateral izquierda y el $20 \%$ fue por esternotomía media. No se realizó estudio imagenológico previo a la cirugía en ningún paciente. En 28 pacientes se indicó cirugía inmediata, en los otros 8 casos se indicó la toracotomía después de $20 \mathrm{mi}-$ nutos desde el ingreso. La principal cámara cardíaca afectada fue el ventrículo derecho (Tabla 1). La mortalidad, fue 16,6\%, 5 fallecidos en pabellón (2 por arma de fuego y 3 por lesiones complejas) y 1 fallecido en el postoperatorio inmediato (falla multiorgánica). La morbilidad fue 22,8\% (Tabla 2). La estadía hospitalaria promedio fue 14 días.

Tabla 1. Lesiones penetrantes cardíacas

\begin{tabular}{lc}
\hline & n \\
\hline Ventrículo derecho & 24 \\
Ventrículo izquierdo & 8 \\
Aurícula derecha & 3 \\
Aurícula izquierda & 1 \\
\hline
\end{tabular}


Tabla 2. Morbilidad postoperatoria

\begin{tabular}{ll}
\hline & n \\
\hline Hemopericardio (reoperado) & 2 \\
Neumonía & 4 \\
Derrame pleural & 1 \\
Sepsis por cateter venoso central & 1 \\
\hline
\end{tabular}

\section{Discusión}

Entre el $60 \%$ y $80 \%$ de los traumas penetrantes cardíacos mueren antes de llegar a la Unidad de Emergencia (UE), de los pacientes que ingresan con signos de vida la mortalidad varía entre un $8 \%$ y $81 \%{ }^{1,4,5}$. El pronóstico depende fundamentalmente de las condiciones fisiológicas del paciente al ingreso, la rapidez del equipo para realizar el tratamiento y probablemente de si presenta ritmo sinusal antes de la cirugía ${ }^{6}$. Creemos que los buenos resultados obtenidos se deben en parte a que el rescate prehospitalario de nuestro hospital (sistema americano) y la geografía de Valparaíso, permiten trasladar al paciente rápidamente a la UE.

La presentación clínica de la lesión penetrante cardíaca se manifiesta desde el paciente clínicamente asintomático y con hemodinamia estable hasta el paciente en shock y paro cardiorrespiratorio (PCR). En nuestro estudio observamos que la principal forma de presentación es el colapso circulatorio. La forma de presentación del trauma penetrante cardíaco depende de varios factores como el mecanismo del trauma, tiempo transcurrido del traslado, magnitud de la lesión cardíaca, PCR en UE y presencia o no de taponamiento cardíaco ${ }^{7,8}$. Luego del manejo del ABC del trauma, nosotros no realizamos otro estudio diagnóstico, fundamentalmente porque los pacientes llegan con colapso circulatorio y porque no disponíamos de ecografía fast. En el trauma penetrante cardíaco, si el paciente se encuentra estable se puede estudiar con radiografía de tórax, aún siendo poco sensible, en la que se podría observar un ensanchamiento del mediastino o un neumomediastino. El electrocardiograma es inespecífico en el trauma penetrante cardíaco $^{8,9}$.

La ecografía fast de urgencia o ecografía bidimensional es el método diagnóstico que más información aporta, permite detectar un mínimo sangrado de $50 \mathrm{ml}$ y tiene una especificidad del 97,3\% y una sensibilidad entre el $90 \%$ a $100 \%$ en el trauma cardíaco $^{1,8,10}$. La ventana pericárdica subxifoídea, descrita por Larrey en el siglo XIX, aún se conside- ra el patrón de oro para diagnosticar un taponamiento cardíaco, sin embargo, ha sido reemplazada por la técnica de ecofast ${ }^{1,8,9}$.

Respecto a la pericardiocentesis, recomendada en el curso ATLS, nosotros no la utilizamos de forma rutinaria ya que los falsos negativos de esta técnica oscilan desde el $7 \%$ al 20\%, sin embargo, como maniobra de traslado aún es recomendada ya que la extracción de $30 \mathrm{cc}$ de sangre permitiría dar unos minutos para llevar al paciente a pabellón ${ }^{8,11}$.

En una de las mayores revisiones de trauma penetrante cardíaco, 1.802 casos, se observó que el $43 \%$ de las lesiones comprometían el ventrículo derecho, un $33 \%$ el ventrículo izquierdo y un $14 \%$ la aurícula derecha ${ }^{12}$, distribución similar a lo reportado por nosotros. Los grandes vasos se comprometen en el $30 \%$ de los traumatismos, la lesión aislada de las arterias coronarias se presenta en el $4 \%{ }^{13} y$ la lesión compleja, lesión que compromete adicionalmente, tejidos y estructuras distintos a la pared muscular de las aurículas o ventrículos, se presenta en el $8 \% 1$

La clasificación del trauma cardíaco de la OIS (Organ Injury Scale) resulta difícil de aplicar en la $\mathrm{UE}^{8}$, por ello se prefiere la Clasificación Clínica de Saadia ${ }^{14}$, que es más simple y permite definir una conducta.

Esta clasificación presenta los pacientes con traumatismos cardíacos a la llegada a la urgencia, y los clasifica en 5 grupos para determinar una conducta quirúrgica ${ }^{17}$ :

a) PCR y midriasis arrefléctica: toracotomía en box $\mathrm{UE}+$ reanimación.

b) Shock Hipovolémico: Reanimación + toracotomía en pabellón.

c) Taponamiento cardíaco: toracotomía en pabellón (inmediata).

d) Trauma cardíaco "estable" (triada de Beck): diagnóstico en pabellón ya sea por ventana subxifoídea, eco fast. No recomienda la pericardiocentesis.

e) Asintomático: estudio según criterio clínico + toracotomía según evolución.

La incisión por la cual acceder al tórax debe basarse en la experiencia del cirujano y el mecanismo del trauma, es una decisión difícil y por lo mismo no debe dejar de mencionarse. Nuestro grupo de cirujanos realiza principalmente una toracotomía antero-lateral izquierda, creemos que es debido a la facilidad técnica y a la experiencia que se tiene con este abordaje.

Las incisiones habituales para el trauma penetrante cardíaco son $^{7-9,15,16}$ :

a) Esternotomía media: heridas penetrantes precordiales. 
b) Toracotomía "en libro": lesiones combinadas vasculares cardíacas y del estrecho torácico.

c) Toracotomía posterolateral: lesiones torácicas no cardíacas.

d) Toracotomía anterolateral izquierda: urgencia.

e) Toracotomía anterolateral bilateral: exposición completa del mediastino anterior, del pericardio así como de ambas cavidades torácicas, recordar ligar ambas arterias mamarias internas.

\section{Cardiorrafia de Urgencia en el trauma penetrante cardíaco}

\section{Reparación auricular}

Las lesiones auriculares pueden controlarse con pinza de Satinsky, con cuidado de no lesionar la delgada pared de la aurícula, por lo mismo debe suturarse con suavidad. La sutura auricular puede ser continua o entrecortada con material monofilamento $^{1,8}$.

\section{Reparación ventricular}

La lesión ventricular una vez identificada se debe ocluir digitalmente ${ }^{16}$. La sutura puede realizarse con puntos simples entrecortados $\mathrm{u}$ horizontales tipo "colchonero" o puntos de Halstead. Se recomienda utilizar sutura monofilamento. El reforzar las líneas de sutura en el miocardio friable es una opción utilizada en urgencia. Para ello se puede usar materiales bioprotésicos como Teflón o parche de pericardio. No existe evidencia que apoye el uso de Teflón de forma rutinaria para favorecer la cicatrización de la herida cardíaca ni de que incremente la resistencia del miocardio a la tensión ${ }^{1,8,9}$.

\section{Reparación de las arterias coronarias}

La localización inadecuada de la sutura puede estrechar u ocluir una arteria coronaria o alguna de sus ramas. Se recomienda que las suturas se sitúen por debajo del lecho de la arteria coronaria correspondiente. Las laceraciones de alguna arteria coronaria a nivel distal pueden ligarse. En situaciones extremas, se puede ligar una lesión a nivel proximal, ocasionando un infarto extenso ${ }^{1,8,9}$.

\section{Reparación de las válvulas}

La mayoría de lesiones valvulares son identificadas en el postoperatorio, como un soplo cardíaco. La lesión de la válvula aórtica lleva a diferentes grados de insuficiencia. Las lesiones de la válvula tricúspide y de la válvula pulmonar, son muy raras y relativamente bien toleradas. La lesión valvular mitral (valvas o músculos papilares) es la más frecuente, en general estas lesiones son bien toleradas. Prácticamente todas las lesiones valvulares son de manejo diferido ${ }^{1,8,9}$.

\section{Conclusión}

La principal causa de trauma penetrante cardíaco en nuestra serie fue la lesión por arma blanca, siendo el ventrículo derecho la principal cámara cardíaca afectada. Los resultados quirúrgicos son comparables con otras series, con una mortalidad del $16,6 \%$ y una morbilidad de $22 \%^{12,14-18}$. La mortalidad quirúrgica está relacionada con el retraso de la cirugía, o lesión por arma de fuego, o presencia de lesiones complejas. Aún sigue siendo fundamental el diagnóstico clínico y el manejo precoz.

\section{Referencias}

1. Asensio J, Petrone P, Karida T, Kelly R, Roldan G, Pak-art R, et al. Penetrating cardiac injuries. Complex injuries and difficult challenges. Ulus Travma Derg 2003; 9: 1-16.

2. Coimbra R, Pinto MC, Razuk A, Aguiar JR. Penetrating cardiac wounds: Predictive value of trauma indices and the necessity of terminology standardization. Am Surg 1995; 61: 448-452.

3. Valenzuela M, Cancino P, Cabezas F, Donoso G, De la Torre I. Experiencia en traumatismo torácico. Hospital Valparaíso. Rev Chil Cir 2003; 5: 449-453.

4. Rhee PM, Foy H, Kaufmann C, Areola C, Boyle E, Maier RV, Jurkovich G. Penetrating cardiac injuries: a population-based study. J Trauma 1998; 45: 366-370.

5. Echevarría JR, San Román A. Evaluation and treatment of cardiac injuries. Rev Esp Cardiol 2000; 53: 727735.

6. Asensio J, Berne J, Demetriades D, Chan L, Murria J, Falabella A, et al. One hundred five penetrating cardiac injuries: a two year prospective evaluation. J Trauma 1998; 44: 1073-1082.

7. Asensio J, Petrone P, Roldán G, Pak-art R, Salim A. Lesiones cardíacas penetrantes. Revisión de nuestra experiencia en LAC+USC medical center. Revista Argentina de Medicina y Cirugía del Trauma 2002; 3: 41-49.

8. Asensio J, Ceballos J, Forno W, Torcal J, Gambado $\mathrm{E}$, Chahwan $\mathrm{S}$, et al. Lesiones cardíacas penetrantes. Una revisión desde sus orígenes históricos hasta las últimas fronteras en el nuevo milenio. Cir Esp 2000; 67: 64-72.

9. Méndez E, Zamora J, Zeledón F, Zamora F. Trauma cardíaco: una revisión práctica II Parte. Rev Costarric Cardiol 2005; 7: 39-46.

10. Rozycki G, Feliciano D, Ochsner G. The role of ultrasound in patients with posible penetrating cardiac wounds: A prospective multicenter study. J Trauma 1999; 46: 543-552.

11. Arom KV, Richardson JD, Webb G, Grover FL. Subxiphoid Pericardial Window in Patients with 
Suspected Traumatic Pericardial Tamponade. Annals of Thoracic Surgery 1977; 23: 545-549.

12. Karrel R, Shaffer MA, Franaszek JB. Emergency diagnosis, resuscitation, and treatment of acute penetrating cardiac trauma. Annals of Emergency Medicine 1982; 11: 504-517.

13. Rea WJ, Sugg WL, Wilson LC. Coronary artery laceration: An analysis of 22 patients. Annals of Thoracic Surgery 1969; 7: 518.

14. Saadia R, Levy RD, Degiannis E, Velmahos GC. Penetrating cardiac injuries: clinical classification and management strategy. Br J Surg 1994; 81: 1572-1575.

15. Bernal A. Traumatismo cardíaco en Medellín. Expe- riencia personal 1968-1992: lecciones aprendidas. Rev Med 2006; 14: 34-39.

16. Phelan H, Patterson S, Hassan M, González R, Rodning C. Thoracic damage-control operation: principles, techniques, and definitive repair . J Am Coll Surg 2006; 203: 933-941.

17. Karrel R, Shaffer MA, Franaszek JB. Emergency diagnosis, resuscitation, and treatment of acute penetrating cardiac trauma. Annals of Emergency Medicine 1982; 11: $504-517$.

18. Landell J, Villamil R, del Risco C, Pérez R. Trauma cardíaco penetrante. Estudio multicéntrico en la provincia las tunas. Rev Cubana Cir 2001; 40: 180-183. 